\title{
Filling Gaps: Moving Toward Better Treatment of Children With Atopic Dermatitis
}

\author{
Robert Sidbury, MD, MPH
}

I t is a brand-new day for the treatment of children with severe inflammatory skin diseases. Not coincidentally, it also is a new day for the treatment of atopic dermatitis (AD). Why?

Historically, children have largely been ignored by pharmaceutical companies and the US Food and Drug Administration (FDA). Drug trials of new medications have been the exclusive province of adults; therefore, information they have generated has had only derivative relevance to the pediatric population. Pediatricians and providers who care for children, aware that they are not simply"little adults," have been forced to extrapolate best practices.

My institution is poised to enroll a 3-year-old child with severe $\mathrm{AD}$ into a biologic trial (ClinicalTrials.gov identifier NCT03346434). The age range for this study is 6 months to 6 years. This extraordinary democratization of clinical trials is no accident. The Best Pharmaceuticals for Children Act, which was passed in 2002, was a first step. This legislation incentivized pharmaceutical companies to include children, who are notoriously more costly to study for myriad reasons, by extending patent protection for approved medications. Subsequent efforts spearheaded by advocacy groups such as the National Eczema Association included the production of guidance documents for industry ${ }^{1}$ and presentations directly to the FDA's Dermatologic and Ophthalmic Drugs Advisory Committee meeting punctuated by powerful patient testimonials. $^{2}$

Serendipitously, AD, a disease that presents by kindergarten in up to $90 \%$ of affected individuals, also has caught the eye of the pharmaceutical industry. Remarkable advances in the understanding of AD inflammation have led to an explosion of new therapeutic targets of interest. By way of context, between the introduction of topical calcineurin inhibitors in 2001 and the FDA approval of dupilumab and crisaborole in 2017, there were precisely zero new molecules approved for the treatment of AD.
Viewed through another lens, prior to 2017, the only FDA-approved systemic medication for AD was prednisone, a drug most AD experts would list as the least appropriate choice for treatment of this condition.

Fast-forward to 2020 and we have a plethora of new possibilities. The National Eczema Association's research web page (https://nationaleczema.org/research/eczematreatment-research/) reveals no fewer than 24 systemic agents in phase 2 development or beyond, including selective IL-13 inhibitors such as tralokinumab and lebrikizumab; Janus kinase inhibitors such as baricitinib ${ }^{3}$; and novel targets such as histamine 4 (ZPL-3893787), IL-31 (nemolizumab), and thymic stromal lymphopoietin. This list does not even include other biologics being repurposed for $\mathrm{AD}\left(\mathrm{eg}\right.$, omalizumab $\left.{ }^{4}\right)$ or a host of exciting new topical agents (eg, tapinarof).

This confluence of better science, powerful advocacy, and enlightened self-interest has been revolutionary. It is most evident when parents/guardians-many of whom had long ago given up on new therapies for themselvesare gobsmacked by the new therapeutic landscape outlined for their children. Parents/guardians realize their children need not struggle as they may have themselves. The impact on quality of life has long been known, but several recent publications have brought it into finer relief. Drucker et $\mathrm{al}^{5}$ highlighted the overall burden of disease, and several subsequent papers have focused specifically on affective impacts including increased risk for depression, suicidal ideation, and suicide. ${ }^{6,7}$ In this issue of Cutis, Tracy et $\mathrm{al}^{8}$ provide an update on pediatric AD with an emphasis on comorbidities, quality of life, and evolving practices and therapies.

Better science, better drugs, better advocacy, better outcomes - it has not been a straight line, but it has indisputably been a forward-marching one. It is a new day, indeed.

From the Department of Pediatrics, University of Washington School of Medicine, Seattle, and the Division of Dermatology, Seattle Children's Hospital. Dr. Sidbury is an investigator for Brickell Biotech, Inc; Galderma Laboratories, LP; and Regeneron Pharmaceuticals. He also is a consultant for Micreos.

Correspondence: Robert Sidbury, MD, MPH (Robert.sidbury@seattlechildrens.org).

doi:10.12788/cutis.0044 


\section{REFERENCES}

1. Siegfried EC, Jaworski JC, Eichenfield LF, et al. Developing drugs for the treatment of atopic dermatitis in children ( $\geq 3$ months to $<18$ years of age): draft guidance for industry [published online March 30, 2018]. Pediatr Dermatol. 2018; May 35:303-322.

2. Pediatric trials for $\mathrm{AD}$ systemic treatments. Dermatology Times. May 21, 2015. https://www.dermatologytimes.com/view/pediatrictrials-ad-systemic-treatments. Accessed August 11, 2020.

3. Solimani F, Meier K, Ghoreschi K. Emerging topical and systemic JAK inhibitors in dermatology. Front Immunol. 2019;10:2847.

4. Chan S, Cornelius V, Cro S, et al. Treatment effect of omalizumab on severe pediatric atopic dermatitis: the ADAPT randomized controlled trial. JAMA Pediatr. 2019;174:29-37.
5. Drucker AM, Wang AR, Li W-Q, et al. The burden of atopic dermatitis: summary of a report for the National Eczema Association [published online September 8, 2016]. J Invest Dermatol. 2017;137:26-30.

6. Sandhu JK, Wu KK, Bui T-L, et al. Association between atopic dermatitis and suicidality: a systematic review and meta-analysis. JAMA Dermatol. 2019;155:178-187.

7. Patel KR, Immaneni S, Singam V, et al. Association between atopic dermatitis, depression, and suicidal ideation: a systematic review and meta-analysis [published online October 23, 2018]. J Am Acad Dermatol. 2019;80:402-410.

8. Tracy A, Bhatti S, Eichenfield LF. Update on pediatric atopic dermatitis. Cutis. 2020;106:143-146. 